\title{
PARTICIPATORY APPROACH TO IDENTIFY INTERVENTIONS TO IMPROVE THE HEALTH, SAFETY, AND WORK PRODUCTIVITY OF SMALLHOLDER WOMEN VEGETABLE FARMERS IN THE GAMBIA
}

\section{LONDA VANDERWAL ${ }^{1}$, RISTO RAUTIAINEN ${ }^{1,2}$, MARIZEN RAMIREZ ${ }^{1}$, REX KUYE ${ }^{3}$, CORINNE PEEK-ASA ${ }^{1}$,} THOMAS COOK ${ }^{1}$, KENNITH CULP ${ }^{4}$, and KELLEY DONHAM ${ }^{1}$

${ }^{1}$ The University of Iowa, Iowa City, Iowa, USA Department of Occupational and Environmental Health, College of Public Health

${ }^{2}$ College of Public Health, University of Nebraska Medical Center, Omaha, Nebraska, USA

Department of Environmental, Agricultural, and Occupational Health

${ }^{3}$ University of The Gambia, Brikama, The Gambia

School of Public Health

${ }^{4}$ University of Iowa, Iowa City, Iowa, USA

Occupational Health Nursing Program, College of Nursing

\begin{abstract}
Objective: This paper describes the qualitative, community-based participatory approach used to identify culturally-acceptable and sustainable interventions to improve the occupational health, safety, and productivity of smallholder women vegetable farmers in The Gambia (West Africa). Materials and Methods: This approach was used to conduct: 1) analysis of the tasks and methods traditionally used in vegetable production, and 2) selection of interventions. Results: The most arduous garden tasks that were amenable to interventions were identified, and the interventions were selected through a participatory process for further evaluation. Conclusions: Factors contributing to the successful implementation of the participatory approach used in this study included the following: 1) ensuring that cultural norms were respected and observed; 2) working closely with the existing garden leadership structure; and 3) research team members working with the subjects for an extended period of time to gain first-hand understanding of the selected tasks and to build credibility with the subjects.
\end{abstract}

Key words:

Vegetable production, Community-based participatory research, Occupational health and safety,

Worker productivity, West Africa

This work was primarily carried out through funding from the University of Iowa Heartland Center for Occupational Health and Safety (Grant number: T42OH008491-04) pilot grant and traineeship programs. More information on project funding is available in the Acknowledgements section.

Received: June 28, 2010. Accepted: September 1, 2010.

Address reprint requests to R. Rautiainen, University of Nebraska Medical Center, Swanson Hall 3058, Omaha, NE 68198-5110, USA (e-mail: rrautiainen@unmc.edu). 


\section{INTRODUCTION}

Many smallholder women farmers in developing countries such as The Gambia (West Africa) are becoming engaged in vegetable farming, which provides healthy produce for their families and a potential source of a much-needed income through the sale of the farm crop [1]. However, vegetable farming in both the developed and developing countries is very demanding on the worker as it involves long hours of hazardous repetitive manual labor, awkward working postures, and often a lack of safety precautions $[2,3]$. In the developed countries [4-6], where improved mechanization is used for at least some tasks, these working conditions have been shown to lead to musculoskeletal disorders/discomfort and injuries. However, even fewer improvements have occurred to the implements or work practices used in vegetable farming systems in the developing countries [7,8].

Alleviation of the arduous nature of smallholder vegetable farming, particularly in the developing countries, requires a multi-faceted approach, including consideration of worker health and safety, cultural norms, resource limitations, and worker productivity. Accordingly, these smallholder farmers should be closely involved in selecting interventions to improve their farming system, to ensure that these interventions actually meet all their long-term needs. [8]

Numerous projects in various occupations have involved the workers in selecting interventions that would help improve their working conditions [9]. Such an approach is known as a participatory approach, which has been defined in the field of ergonomics as "the involvement of people in planning and controlling a significant amount of their own work activities, [...] to influence both the processes and outcomes in order to achieve desirable goals" [10]. Many researchers working for labor-intensive agriculture in the USA [11-13] have applied this participatory approach to involve workers and their managers in the design, evaluation, and implementation of interventions to reduce work-related injuries and musculoskeletal discomfort. Compared to a traditional approach where the workers are not involved in selecting the tasks or interventions to be evaluated, the participatory approach has been shown to improve health outcomes, increase worker productivity, and reduce risk factors for injuries [9]. The use of the participatory approach also helps to raise worker morale, improve the general working environment, ensure relevance to the workers' social environment, and increase long-term use of the interventions selected $[11,14,15]$.

Despite the benefits, few agricultural projects in the developing countries have implemented the participatory approach that involves the beneficiaries of an intervention (particularly when they are women) in its selection and evaluation. Thus, little information is available on the methods used to conduct such research $[7,8,16]$. In many developing countries, women - particularly farm women - are given little freedom to make decisions, although they have extensive practical knowledge and ideas on how to improve their situation. Involving the women in the selection of interventions could help increase the likelihood that they will continue to make use of these interventions [7,16]. Therefore, the participatory approach would be very useful in conducting research with women vegetable farmers in countries such as the Gambia.

Accordingly, the overall aim of this paper is to describe the participatory approach used to select the culturallyacceptable, sustainable interventions to improve the occupational health, safety, and productivity of smallholder women vegetable farmers in The Gambia.

Specifically, this article will describe the approaches used for the following phases of the study:

1. Analysis of the tasks and methods traditionally used in vegetable production.

2. Selection of interventions using a community-based participatory process. 
As indicated in Figure 1, the overall mixed-methods research project that this study was a part of also includes the evaluation of the interventions selected, which are reported elsewhere [17].

\begin{tabular}{|l|l|l|l|}
\hline $\begin{array}{l}\text { Phase 1 and 2. } \\
\text { Qualitative: } \\
\text { analysis of work tasks } \\
\text { and participatory } \\
\text { selection of interventions } \\
\text { to test }\end{array}$ & $\longrightarrow \begin{array}{l}\text { Phase 3. } \\
\text { Quantitative: } \\
\text { testing effectiveness of } \\
\text { interventions (health, } \\
\text { safety, and productivity) }\end{array}$ \\
\cline { 2 - 3 }
\end{tabular}

Fig. 1. Overall mixed-methods project design.

\section{METHODS}

\section{Research Setting}

The research was conducted in a community vegetable garden outside a small village in The Gambia, a small developing country in West Africa (see map in Figure 2). A local non-governmental organization (NGO), which oversees the garden, willingly cooperated with the research team in implementing this study. The "research team" referred to in this paper (later denoted as "we") consists of the principal investigator (PI, first author) and the local project assistants as described below, with considerable advice and input from the other authors of this paper.

\section{Subjects}

A total of 212 women from the village work in the garden, each in her own plot. The women are divided into 12 work groups, based on the geographic location of their plot within the garden. Each group has a selected leader. These 12 leaders are generally chosen for their farming ability, their leadership and communication skills, and their years of garden experience (K. Ceesay, garden manager, Personal Communication, 2009), and thus served as key informants in the study. These leaders are not in a supervisory role, but are available to provide advice and often assist in sharing information between members of their group and the NGO overseeing the garden. To maintain the garden

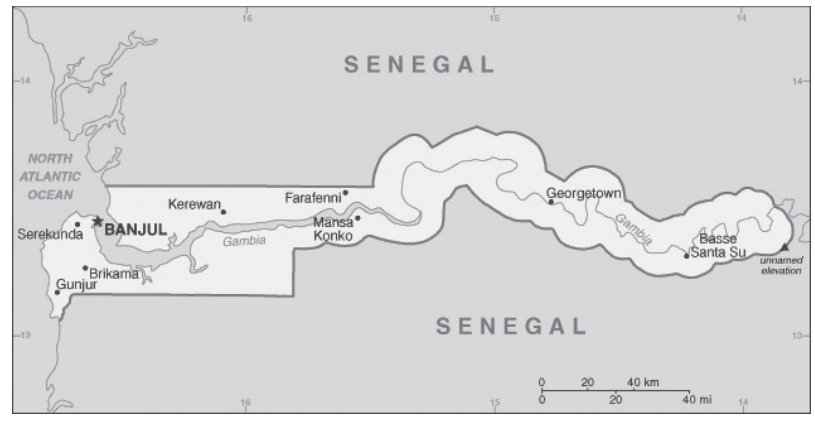

Map source: US Central Intelligence Agency.

Fig. 2. Map of The Gambia, West Africa.

leadership's support for the project, it was important that each work group leader was a subject in this project. Three other women from each of the 12 working groups were also randomly selected to participate.

The research team met with the 48 subjects to introduce the study objectives and administer informed consent in Mandinka, the local language. The study protocol was approved by The Gambia Human Ethics Committee (SCC/EC \#1123) and the University of Iowa Institutional Review Board (IRB ID\# 200808704) in accordance with the Helsinki Declaration on ethical testing with human subjects. All the selected women (more information on their demographics is available in reference no. 17) consented to participate in the study. The subjects were provided with a small monetary gift for their participation, which was not made known to them until the end of the study to reduce the likelihood that the subjects would feel compelled to provide responses which they felt would please the researchers.

\section{Project assistants}

The Gambian employee of the local NGO already working as an advisor to the women in the garden served as the main interpreter and liaison between the research team and the subjects in the project. Selected students from an Occupational Health course at the Gambia College were extensively trained to serve as the project assistants, mainly collecting physiological data and conducting interviews (in Mandinka). 
General conduct of individual interviews

Two research assistants conducted two rounds of informal, qualitative individual interviews with the 12 work group leaders (considered key informants) in the garden, as well as with another 12 randomly selected subjects while they were working in their plot, and wrote down the results on an open-ended form. The content of the interviews is described in the relevant section below. All the data collection instruments used throughout the study were developed in English and translated into the local language of Mandinka, with extensive input from the local research team members.

\section{General conduct of focus group discussions}

We used the existing leadership structure of the garden and respected the cultural norms of the subjects in holding three participatory focus groups during this study. Although focus groups typically include 6-8 people [18], discussions with the Gambian research assistants and the garden leadership indicated that it was culturally important to have all 12 of the garden work group leaders take part in each of the focus group discussions. All the subjects were welcome to attend and listen to the focus group discussions, but only the 12 leaders contributed, in accordance with the cultural norms.

The discussions were facilitated by one of the local research assistants and conducted at the vegetable garden in the local language, with the first two focus groups lasting approximately 1-1.5 hours, and the third lasting $30 \mathrm{mi}$ nutes. The discussions were digitally recorded (with the permission of the group), translated from Mandinka into English and transcribed by the local project assistants. Hand-written notes of a simultaneous English interpretation (by a local project assistant) were also taken and later typed by the PI. The typed notes (in English) were checked for accuracy by the focus group facilitator and compared with the discussion tapes (in the local language), as necessary, to verify the content of the discussion.
Methods for assuring participation of subjects

in selecting tasks and interventions

The participatory approach was developed and implemented in this study during two main phases, as described below.

\section{Phase 1. Analysis of the tasks and methods traditionally used in vegetable farming}

Subject observations

The subjects were observed, primarily over a four-week period of time, during their routine work in the garden in order to note the tasks normally undertaken, the tools used, and to make general observations of inefficiencies, discomfort and particularly injury-prone tasks. The PI and the same two research assistants used an open-ended form to document the observed activities and behaviors of the subjects in the garden.

Themes of first individual interviews and focus group discussion

In the first round of individual interviews and focus group discussions, the subjects were asked for in-depth information regarding a) the various tasks undertaken in the garden; b) the amount of time generally spent on those tasks and the time of the year the tasks are performed; c) the pains, injuries, and inefficiencies in these tasks; d) the tools used and their rationale for the use of those tools; and e) practical suggestions for low-cost tools/interventions to improve the safety and efficiency of their work.

An agricultural technology specialist from the Gambian National Agriculture Research Institute also participated in the first focus group discussion to provide insight into the possible improvements to the methods currently used, as well as input on the feasibility of locally re-producing interventions.

Selection of tasks for intervention

The research team discussed the outcomes of the subject observation, individual interviews, and the first focus group discussion, as well as previous work by other researchers 
and prior experience, and they agreed upon the tasks that were the most painful, injury-prone, and time-consuming. The team then discussed which of these tasks were most amenable to low-cost intervention, which could be objectively evaluated in the course of the study. The research team then agreed on the three tasks (land preparation, water lifting, and vegetable transport) to be addressed in the remainder of the study, and sought the approval of the subjects on the tasks selected. In this way, a logic model framework [19] was used to identify the tasks for intervention.

\section{Phase 2. Selection of interventions}

Provision of intervention models

Based on the results of Phase 1, the research team provided models of locally-available/reproducible tools for the three tasks identified, and left them with the subjects for one-week testing. These models included 14 long- and short-handled hoes (some shipped from the USA and some purchased locally) for land preparation, information on various water lifting pumps, and a flat plastic crate with handles for transporting vegetables.

Themes of second interview round

and focus group discussion

In the second round of interviews and focus group discussion, the subjects were asked for feedback on the model interventions, as well as for any other ideas on other feasible methods, or modifications to existing methods, to improve the three garden tasks.

Selection of interventions to be evaluated In addition to the results of the activities in Phase 1 and 2, the research team discussed the interventions to be evaluated for each of the three tasks, based on the following criteria:

- Intervention was perceived by research team as likely to improve worker safety, comfort, and/or efficiency;
- Intervention was locally available/reproducible, reasonably priced, and easy to maintain locally;

- Impact of intervention could be clearly evaluated within the course of the study.

Based on this information, the research team selected the two or three most promising interventions for each task. A brief third focus group was then held to allow the subjects to provide feedback on these choices and to provide input on the intervention they preferred for each task.

\section{Data analysis}

All the qualitative information gained through subject observation, individual interviews, and focus groups was analyzed to identify the patterns and common themes. A purposeful, deductive approach was used in this research, where the information gathered was used to draw specific conclusions regarding the tasks for which interventions should be developed, and the interventions that should be selected for further research. Similar approaches have been successfully used in other women's health and development projects in Africa [20,21].

The PI worked with the local project team and the focus group facilitator to interpret the focus group data both during and immediately after the discussions. The coding of interviews and subject observations were discussed with the local project assistants immediately after completion. All the opinions expressed by the subjects were included in the analysis, with special regard to the number of subjects reporting on a particular point.

\section{RESULTS}

\section{Rationale for selecting tasks and interventions}

Based on the previously described methods to develop and implement a participatory approach, the following information emerged, providing a rationale for the decisions on the tasks and interventions in Phases 1 and 2 of the study. 
Phase 1. Vegetable farming tasks

and traditional methods used

The main tasks undertaken in the vegetable farming system in this study were identified as follows: a) land preparation; b) planting; c) weeding; d) watering; e) harvesting; and f) transporting. The amount of work time, the tools commonly used, and the pain and injuries often incurred during these tasks are described below. The tasks selected for intervention are also described.

\section{Land preparation}

Although land preparation lasts for only two weeks per growing season, the subjects estimated that the task required 3-4 hours of heavy labor per day during this period. The research team observed that the subjects typically used a locally-made, light, short-handled hoe with a dull metal cutting surface. The subjects stated that this task is very injury-prone, saying (in Mandinka), "I si fay baramano le" ("you can easily injure yourself"). The research team admitted that this is likely because the subjects swing their hoes forcefully towards the ground to till the soil, with the hoe often hitting very close to their bare feet. The subjects also noted that the long hours of forceful, stooped labor also make the task very painful, with one subject stating "I can hardly walk upright after working (in land preparation) even for a short time". Therefore, the research team and the subjects agreed that interventions should be selected for this task.

\section{Planting}

The subjects estimated that in this vegetable farming system, planting generally requires approximately 3 hours of work per day for one week at the beginning of every growing season. The subjects reported that they typically plant seeds/young plants with bare hands and prepare the seed bed with a locally-made short-handled hoe. The research team observed that planting does require stoop labor and repetitive motions, but the small size of each woman's garden plot limits the amount of time needed for planting. One subject noted "a buka wati jamata, woleya tina a mantoro man wara" ("it doesn't take much time; this is why there is less discomfort"). The subjects also commented that it is less injury-prone than the other tasks in vegetable production. Accordingly, this task was not considered a priority for the selection of interventions.

\section{Weeding}

Weeding vegetables is relatively time-consuming; the subjects estimated that it requires approximately 5-6 hours of labor per day for a total of at least 40 days throughout each growing season. The research team observed that the tools used for weeding were typically similar to those used for land preparation, although the subjects also reported using very small (short-handled) bent metal rods for weeding in narrow areas. The subjects emphasized that weeding also requires long hours of repetitive, stooped labor, which makes the job quite painful, and one subject noted that, similar to land preparation, "I si fan baramano le" ("you can easily injure yourself"). However, the research team agreed that it would be difficult to accurately evaluate the differences between the weeding interventions, as the conditions of weeding vary greatly, depending on the species, plant growing density, weed type and density, soil moisture level, etc. Further, the interventions for land preparation would be similar to the interventions for weeding; hence, interventions were selected only for land preparation.

\section{Watering}

One subject stated that watering is "wati jama tale" ("very time-consuming"), which was confirmed by the focus group which estimated that watering required 5 hours per day during the dry growing season (November-May), or $60-70 \%$ of their total work time in the garden. The research team observed the current method where women drop a bucket (5-7 liter plastic bucket) tied to a rope into 
one of the 22 concrete-lined wells in the garden to lift water for their crops, pouring the water into larger buckets (typically a $\sim 15$-liter bucket) and carrying these large buckets, one or two at a time, to their vegetables. We measured that the level of well water in this garden can range from approximately 3 meters at the end of the rainy season to approximately 13 meters at the beginning of the next rainy season. The subjects estimated that they lift 400 liters per day, which would require 80 buckets ( $\sim 5$ liters $/ 5 \mathrm{~kg}$ each) of water per day. Therefore, the subjects stated that water lifting is extremely painful.

Further, one subject noticed that "it is not safe for my children to help (with water lifting), as I am afraid (the child) may fall into the open well". Multiple subjects also reported that "mbulo kabusi le" ("my hand gets blistered and calloused") from the poor quality rope used to lift the buckets. Accordingly, the research team and the subjects agreed to select an intervention for water lifting. The subjects admitted that transporting water from the well to their plot was also time-consuming and painful, but emphasized that water lifting interventions were a higher priority.

\section{Harvesting}

Relative to the other tasks in this vegetable garden, the subjects stated that harvesting is only moderately timeconsuming as it is performed for approximately 4 hours per day for about 20 days at the end of each growing season. We observed that vegetables are typically harvested by hand or by cutting with a small knife. The subjects noted that harvesting can be very painful, and one subject reported that "my back hurts so much when I harvest", as it involves long hours of stoop labor and awkward postures. Because of the relatively small area for each woman in this garden to harvest, and the unavailability of suitable interventions to improve the actual harvesting process, the research team and the subjects agreed to test interventions for the transporting, rather than harvesting, of vegetables.

\section{Transporting}

Depending on the amount of produce and the distance each woman had to travel, the subjects emphasized that transporting the harvested vegetables can be time-consuming, sometimes requiring 10-12 trips from the garden per day at the peak of the harvest season. The research team observed that most women carry their produce in large, deep plastic basins balanced on their head, typically for a distance of at least $1.2 \mathrm{~km}$ from the garden to the main road. The weight carried varies depending on the type of the vegetable, but the research team observed that a common load would be $20 \mathrm{~kg}$ of tomatoes in one basin. Thus, many subjects noted that "a ka kan dimo sabo le" ("it causes neck pain"). The subjects were also concerned about the quality of the tomatoes carried at the bottom of a deep basin, saying "nin ye pano ta menten jama ka taye le" ("if you take a basin, many tomatoes get crushed"). We noted that the handles of the basins often break when the basins are lifted onto the subjects' heads. Accordingly, the research team and the subjects agreed to select interventions for this task.

\section{Phase 2. Interventions selected}

Through the community-based participatory process that was established, the possible interventions for the following tasks were assessed, with the most promising ones selected for evaluation in further studies.

\section{Land preparation}

The subjects recognized that some of the 14 model hoes evaluated were more useful for weeding than for land preparation. However, many of the characteristics that are useful in weeding hoes are also useful in land preparation hoes, so they will be reported here as well.

In this study, the subjects considered the following characteristics to be important in selecting a hoe:

1. Light weight (emphasized many times), however the tool should still maintain the qualities listed below, such as 
2. Strength: ability to dig hard, dry soil without the risk of breakage; a long-lasting; "powerful" tool.

3. Versatility: The subjects thought that the tools that could be used for multiple purposes were more useful.

a. Tools with two-sided heads can be used for more than one operation. One subject stated that "this (two-sided tool) is great as I can use it on one side to dig and on the other side to break up clumps".

b. The subjects with little resources may only be able to afford one hoe, so more versatile equipment is preferable. One subject stated "since getting a new tool is expensive, I have to use one tool for everything".

4. Size: a wider soil-cutting surface to work large areas of ground more quickly; one subject said that "with a (tool with a narrow head), I will be working too long".

5. Familiarity: For example, a stirrup hoe (for weeding), which the subjects had never seen before, was demonstrated and even after the demonstration they admitted that "N man nin jorango la dokuwo fahamu" ("we don't understand the work of this tool").

6. Ease of use: sharp cutting surface on the metal head. One short-handled hoe (which was purchased locally) and one long-handled hoe (shipped from the USA) were selected as the interventions for land preparation to be tested in further studies (see Photo 1).

\section{Water lifting}

The subjects proposed a wide range of the possible interventions for water lifting. The subjects' first proposal was a bore hole well with a motor-driven pump. However, the high cost (> 8000 USD) of installing such a system was prohibitive. The subjects also discussed replacing their frayed, abrasive rope with a stronger, wide and flat cord. The research team then provided information on the number and types of manually-operated water pumps,

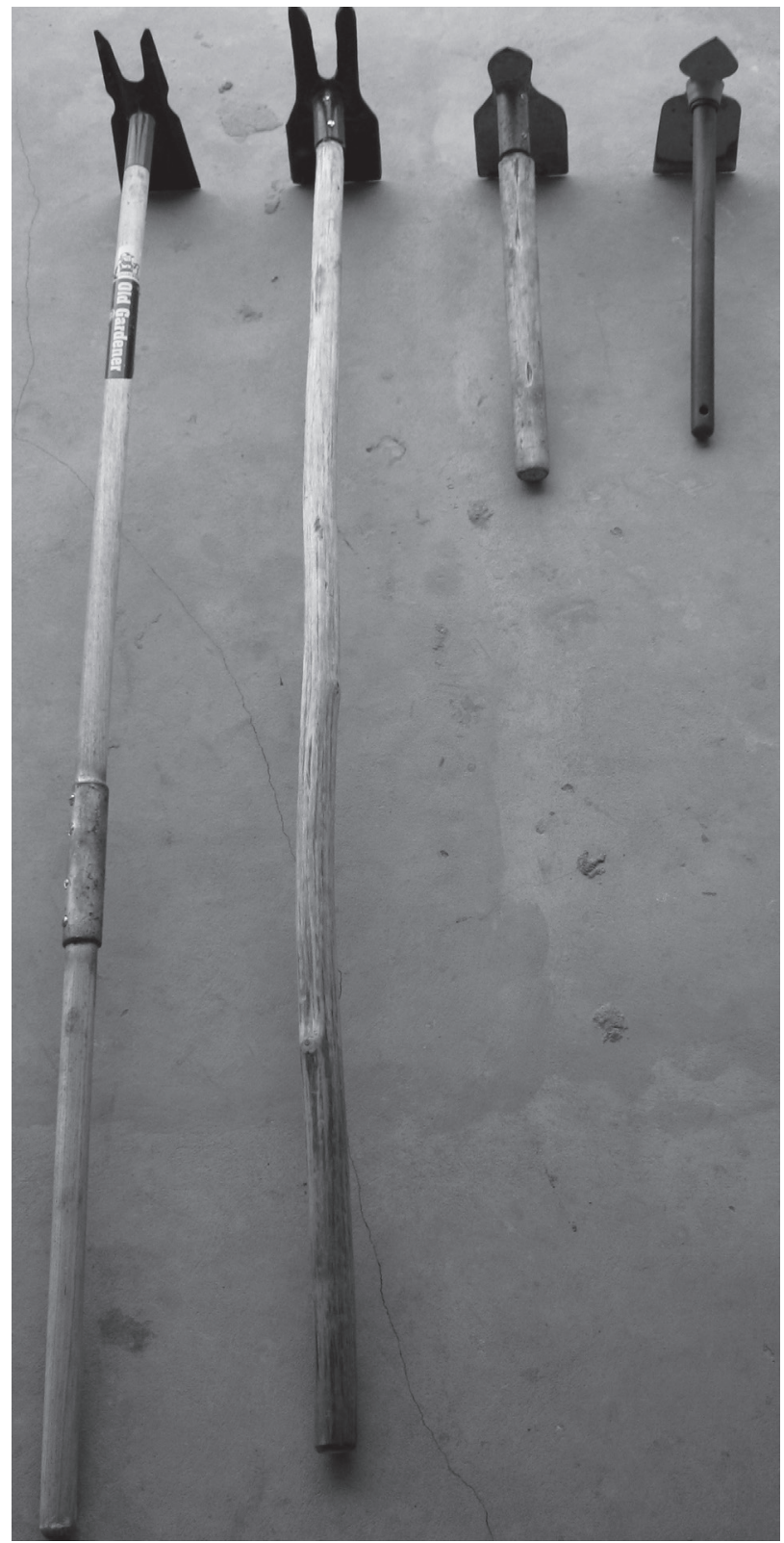

The handle of the model long-handled hoe was cut for shipping to The Gambia and was rejoined with a silver metal tube.

Photo 1. Model hoes selected through the community-based participatory process (on the outside of the photo), with the locally-manufactured short- and long-handled hoes in the center.

including a foot-operated treadle pump. Some subjects recalled that a previous model of a hand-cranked water pump they had used was "a kolaya ta bake" ("too difficult") to pump, but they very willingly agreed to test an 


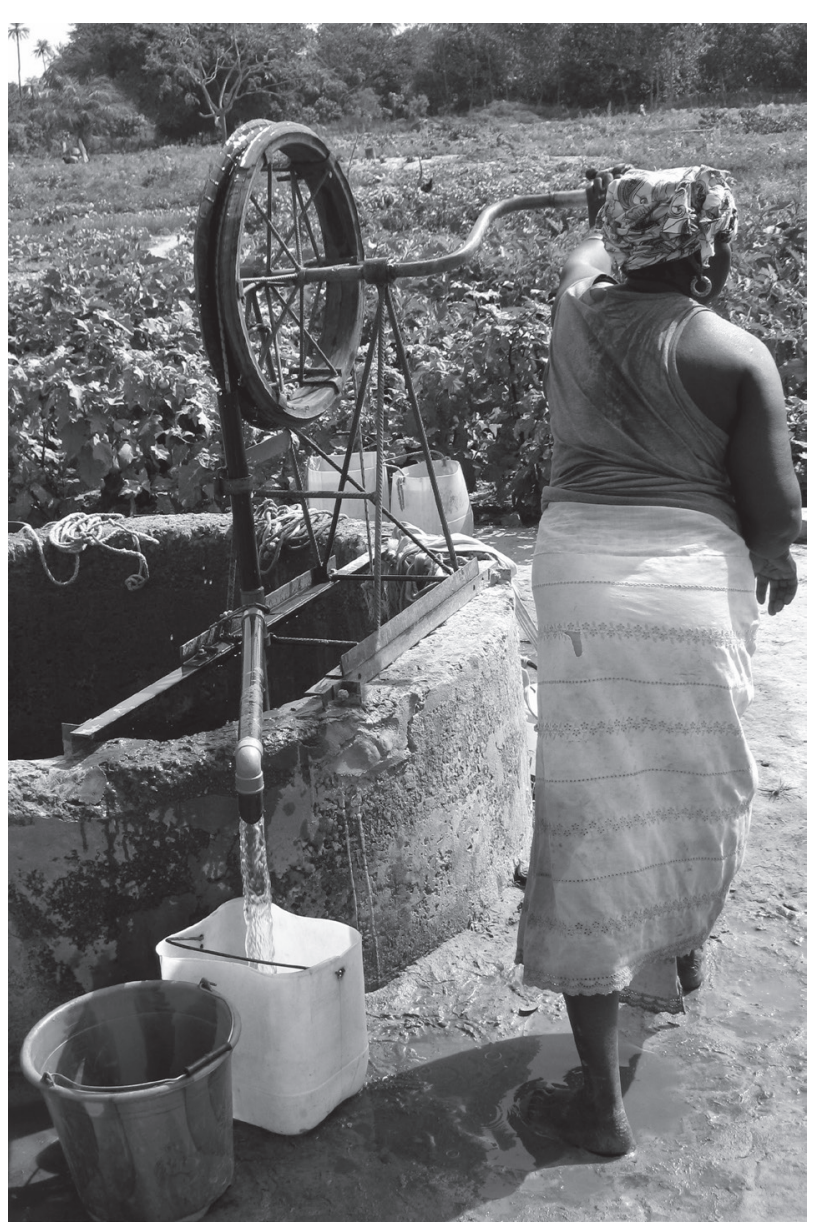

Photo 2. Subjects using hand-operated water pump selected in the study.

improved rope and washer hand pump (see Photo 2). The pump was promoted and sold by an international NGO working in The Gambia, but was manufactured and maintained locally, by the Gambians.

\section{Transportation}

The subjects suggested that large wheelbarrows could be used to improve the transportation of their produce. However, the subjects noted that it would be difficult to move a wheelbarrow through the narrow paths in the garden and that soft produce such as tomatoes "would crush too much" at the bottom of a heavy load when carried over the rough paths leading from the garden. The project team

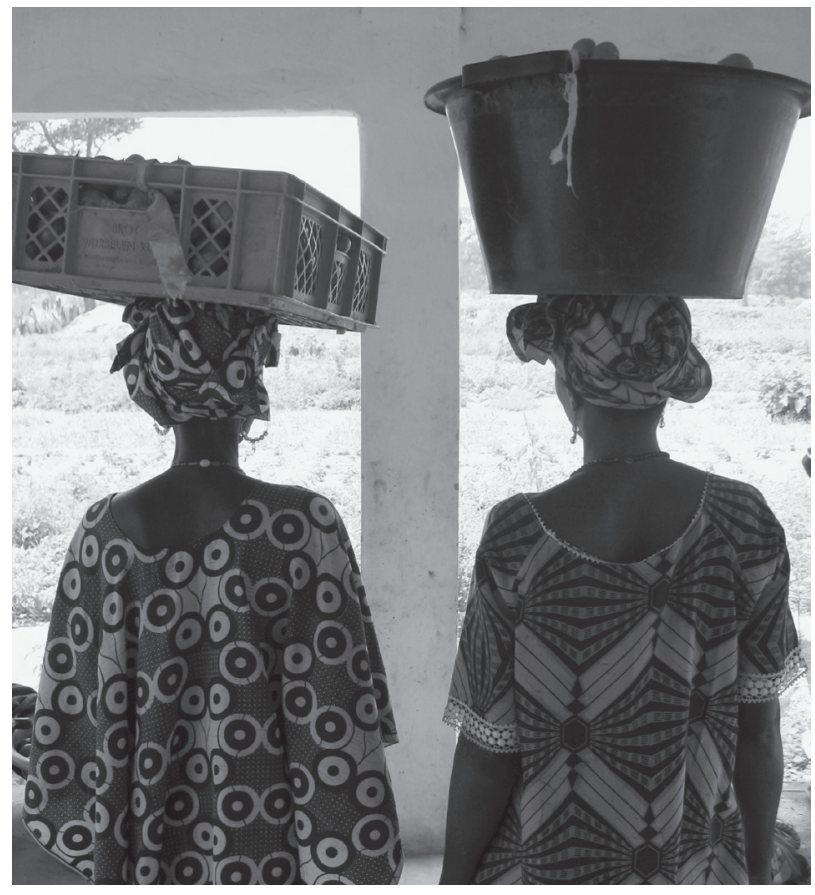

Photo 3. Women transporting tomatoes with a crate (intervention - right) and a traditional plastic basin (left).

showed the subjects some flat, rectangular plastic trays that could be used for transporting vegetables, which were purchased at a garden supply store in the largest city in The Gambia (approximately $40 \mathrm{~km}$ from the garden) for approximately 5 USD each. The subjects had seen similar trays being used by larger-scale vegetable growers in The Gambia, and said "n kontani ta bake" (we are very happy) to test the tray (see Photo 3 ).

\section{DISCUSSION}

The use of the community-based participatory approach described in this paper is well suited to address the complex occupational health and safety, and worker productivity challenges of smallholder vegetable farmers. Other studies have also shown the benefits of applying the participatory process in developing effective interventions as it helps ensure that the products of the research process are more relevant to the needs of the participants, compared to the interventions 
implemented without the participatory approach [22-24]. This is particularly important when developing interventions to assist women farmers in countries such as The Gambia where men are usually responsible for making decisions and for making tools. Therefore, it is essential that women's opinions are also considered and that any tools developed are accessible to them $[8,25,26]$. Further, the participatory approach is beneficial as it allows the subjects to present their own ideas for interventions. Since they know their farming system best and have invaluable local expertise and traditional wisdom, the interventions developed in such a manner can be more effective [27,28].

However, there are also some disadvantages of using the participatory approach to improve worker health, safety, and work productivity. Implementing such an approach is time-consuming, and does not necessarily make use of the best scientific information available, as the subjects may not be well-informed about the ergonomic principles or injury prevention. [9]. The participatory approach also limits the researcher's control of the implementation of the study. In addition, there are many challenges to implementing the participatory approach effectively, which makes it difficult to gain maximum benefits from the subjects' participation [9].

In this study, the use of the participatory approach to analyze and improve the occupational health, safety and productivity of the subjects was effective as it was evident that the women enjoyed being a part of the study, which was confirmed by the $100 \%$ participation rate throughout the project. Furthermore, the feedback on the effectiveness and the acceptance of the interventions, which were evaluated in other studies [17], was generally positive, and more importantly, the subjects provided a reliable and useful feedback.

Such a participative and collaborative approach requires great effort to develop good relationships and credibility with all those involved in the project [3,13,29]. A number of factors were identified as important for the successful application of the participatory approach in this study. These factors included

- ensuring that the cultural norms of the participants were respected and observed during the project preparation and conduct;

- the PI's acquiring some basic greetings and expressions in the local language, which helped to strengthen relationships with the women farmer participants;

- using the existing garden leadership structure and acting in close partnership with the Gambian garden advisor;

- reassuring that the subjects will be working in a nonthreatening and familiar context;

- research team members assisting in every garden task for an extended period of time, to gain first-hand understanding of all the tasks and to build credibility with the subjects.

In addition to its use in a scientific research process as described in this paper, the participatory approach can also be applied in the provision of routine occupational health services, where workers can be involved in the decisionmaking to improve their own working conditions. However, occupational health is only an emerging concept in the Gambia, like in many other West African countries. The Gambian government is in the process of developing an occupational health policy, and has only a few people with some responsibilities for occupational health in the Ministry of Health and in the Department of Labor, who do very little work in the area of agriculture. A labor union does exist in the country, but has a minimal focus on occupational health, and works primarily in factories. Therefore, almost no assistance in occupational health and safety is currently (2010) provided to workers or employers in the Gambia, particularly in agriculture. Considering the above, the implementation of this study provided an excellent opportunity to raise awareness and provide information on occupational health and safety to the garden leadership and the farm workers. 
The study may have been more effective if the subjects were allowed more time to generate ideas for interventions and to pilot test the model tools provided, but the study was conducted within a limited time framework. The interpretation of the discussions from the local language into English and back was time-consuming and tedious at times, but it was critical that the information be interpreted accurately. Also, the data deriving from only one garden may limit the generalization of the results. These points can all be addressed in future studies.

\section{CONCLUSIONS}

The participatory approach described in this study can be directly applied in other smallholder farming settings with a similar leadership structure - which is common throughout Africa and in other developing countries - to improve the occupational health, safety and productivity of the farmers. Workers in labor-intensive vegetable farming systems in the developed countries could also benefit from this approach, as there are similarities between the workforce and work tasks in these systems in the developed and developing countries.

\section{ACKNOWLEDGEMENTS}

The funding for this study was provided by the University of Iowa Heartland Center for Occupational Health and Safety (Grant No. T42OH008491-04) pilot grant and traineeship programs, the University of Iowa Injury Prevention Research Center (Grant No. 1R49CE001167-03)), a Sigma Delta Epsilon / Graduate Women in Science fellowship, a University of Iowa T. Anne Cleary International Dissertation Research Fellowship and a Stanley Graduate Award for International Research, and a University of Iowa Executive Council of Graduate and Professional Students Research Grant. Dr. Rautiainen's contribution was funded by the Great Plains Center for Agricultural Safety and Health (Grant No. 1U50OH009001-01) and his research career award (Grant No. 1KO1OH008300). We wish to express our sincere gratitude to all these organizations for their financial support. We would also like to sincerely thank the staff of the Gambia College, the Trust Agency for Rural Development (TARUD, the local NGO supervising the garden where the research was conducted), and the student research assistants from the Gambia College for all their support and assistance in this study.

\section{REFERENCES}

1. Carney J. Women's Land Rights in Gambian Irrigated Rice Schemes: Constraints and Opportunities. Agric Hum Val 1998;15:325-36.

2. Janowitz D, Tejeda J, Miles V, Duraj J, Meyers M, Faucett J. Ergonomics Interventions in the Manual Harvest of Wine Grapes. In: Proceedings of the Human Factors and Ergonomics Society Annual Meeting; San Diego: Human Factors and Ergonomics Society/International Ergonomics Association; 2000. p. 628-30.

3. Fathallah FA, Miller BJ, Miles JA. Low back disorders in agriculture and the role of stooped work: Scope, potential interventions, and research needs. J Agr Saf Health 2008;14:221-34.

4. Van Dieen JH, Jansen SM, Housheer AF. Differences in low back load between kneeling and seated working at ground level. Appl Ergon 1997;28:355-63.

5. Villarejo D, Baron S. The occupational health status of hired farm workers. Occup Med State Art Rev 1999;14:613-35.

6. National Institute of Occupational Safety and Health (NIOSH). Injuries among Farm Workers in the United States - 1995. Atlanta (GA): Centers for Disease Control; 2009.

7. Rogan A, O'Neill D. Ergonomics aspects of crop production in tropical developing countries: A literature review. Appl Ergon 1993;24:371-86.

8. International Fund for Agricultural Development (IFAD). Agricultural Implements Used by Women Farmers in Africa. Findings of a study conducted in 1998. Gender and development fact sheets [cited 2006 Nov 6]. Available from URL: http:// www.ifad.org/pub/other/lifadafr.pdf. 
9. Hignett S, Wilson JR, Morris W. Finding ergonomic solutions - participatory approaches. Occup Med 2005;55(3): 200-7.

10. Wilson JR. Ergonomics and participation. In: Wilson JR, Corlett EN, editors. Evaluation of Human Work: A Practical Ergonomics Methodology. 2nd ed. London: Taylor and Francis; 1995. p. 1071-96.

11. Baron S, Estill C, Steege A, Lalich N. Simple solutions: Ergonomics for farmworkers. Cincinnati (OH): DHHS (NIOSH); 2001.

12. Earle-Richardson G, Jenkins P, Fulmer S, Mason C, Burdick P, May J. An ergonomic intervention to reduce back strain among apple harvest workers in New York State. Appl Ergon 2005;36:327-34.

13. Faucett J, Meyers J, Miles J, Janowitz I, Fathallah F. Rest break interventions in stoop labor tasks. Appl Ergon 2007;38:219-26.

14. Leung MW, Yen I, Minkler M. Community-based participatory research: a promising approach for increasing epidemiology's relevance in the 21st century. Int J Epidemiol 2004;33:499-506.

15. Cook WK. Integrating research and action: a systematic review of community-based participatory research to address health disparities in environmental and occupational health in the USA. J Epidemiol Community Helath 2008;62:668-76.

16. Kaul R. Labour in agricultural production in Asia and Africa and the need for ergonomic interventions. In: Annevelink E, Oving RK, Vos HW, editors. Proceedings, XXV CIOSTA-CIGR 1993. Farm planning, labour and labour conditions, computers in agricultural management. Wageningen: Wageningen Academic Publishers; 1993. p. 20-7.

17. Vanderwal LS. Improving the health, safety, and productivity of women vegetable farmers in The Gambia [dissertation]. Iowa City (IA): University of Iowa; 2009.

18. Morgan D. Focus Groups as Qualitative Research. 2nd ed. Beverly Hills (CA): Sage Publications; 1997.
19. Alter C, Egan M. Logic modeling: a tool for teaching critical thinking in social work practice. J Soc Work Educ 1997;33: 85-102.

20. Manderson L, Mark T. Empowering women: participatory approaches in women's health and development projects. Health Care Women Int 1997;18:17-30.

21. Vallely A, Shagi C, Kasindi S, Desmond N, Lees S, Chiduo B, et al. The benefits of participatory methodologies to develop effective community dialogue in the context of a microbicide trial feasibility study in Mwanza, Tanzania. BMC Public Health 2007;7:133-8.

22. Rosecrance J, Cook T. The use of participatory action research and ergonomics in the prevention of work-related musculoskeletal disorders in the newspaper industry. Appl Occup Environ Hyg 2000;15:255-62.

23. Vink P, van Eijk DJ. The effect of a participative product design process on user performance. Safety Sci 2007;45:567-77.

24. Rivilis I, Van Eerd D, Cullen K, Cole DC, Irvin E, Tyson J, et al. Effectiveness of participatory ergonomic interventions on health outcomes: A systematic review. Appl Ergon 2008;39:342-58.

25. Kaul R, Ali A. Gender Issues in African Farming. A case for developing farm tools for women. J Farm Systems Res Exten 1992;3:35-46.

26. Egharevba R, Iweze F. Sustainable agriculture and rural women: Crop production and accompanied health hazards on women farmers in six rural communities in Edo state Nigeria. J Sustain Agr 2004;24:39-51.

27. International Labor Organization (ILO). Working conditions: Agricultural workers 2005 [cited 2007 Oct 8]. Available from: http://www.ilo.org/public/english/protection/condtrav/ workcond/agriwork/agricult.htm.

28. Hellin J, Bellon M, Badstue L. Bridging the gaps between researchers' and farmers' realities. LEISA Magazine 2006;22:3-7.

29. Rogers E. Diffusion of innovations. New York: Free Press; 2003.

This work is available in Open Access model and licensed under a Creative Commons Attribution-NonCommercial 3.0 Poland License - http://creativecommons.org/ licenses/by-nc/3.0/pl/deed.en. 